\title{
Динамика естественного движения населения на Северном Кавказе в постсоветский период
}

\author{
А.В. Казалиева ${ }^{凶}$, В. В. Миненкова \\ Кубанский государственный университет, Российская Федераџия \\ (350040, г. Краснодар, ул. Ставропольская, 149)
}

\begin{abstract}
Аннотация: Цель - проведение анализа соотношения общих коэффициентов рождаемости и смертности, что позволило представить общую картину изменения численности населения в результате его естественного движения в национальных республиках Северного Кавказа, а также в Ставропольском и Краснодарском крае в постсоветский период. На основании анализа коэффициентов естественного движения населения раскрыть основные закономерности и тенденции воспроизводства в региональной и субрегиональной структуре. Meтоды. Показатели сведены в динамические ряды, а также распределены по городским и сельским поселениям. Результаты. Коэффициенты рождаемости, смертности и естественного прироста населения на Северном Кавказе имеют ярко выраженную региональную дифференциацию, которая в последние годы стала более очевидной. При том, что на сегодняшний день анализируемые показатели имеют повсеместную тенденцию к постепенному снижению, первые два десятилетия после распада СССР в ряде национальных субъектов Северного Кавказа произошел демографический «взрыв» на фоне нулевого естественного прироста в русскоязычных регионах. Выявлена так же поселенческая специфика естественного воспроизводства населения. В русскоязычных Ставропольском и Краснодарском краях, а также в республиках Адыгея и Северная Осетия естественный прирост выше среди городского населения, в остальных субъектах Северного Кавказа естественный прирост в сельской местности преобладает над городским.
\end{abstract}

Ключевые слова: рождаемость, смертность, естественное воспроизводство, естественное движение населения, городское население, сельское населения, Северный Кавказ.

Для цитирования: Казалиева А.В., Миненкова В.В. Динамика естественного движения населения на Северном Кавказе в постсоветский период // Вестник Воронежского государственного университета. Серия География. Геоэкология, 2020, №3, с. 49-55. DOI: https://doi.org/10.17308/geo.2020.3/3023

\section{ВВЕДЕНИЕ}

Происходящие в последние десятилетия социально-экономические преобразования в стране привели к острым демографическим проблемам, главная из которых - депопуляция населения, обусловленная преобладанием уровня смертности над уровнем рождаемости.

В изучении актуальных вопросов естественного воспроизводства населения важную роль играет ретроспективный анализ, проводимый с целью выявления динамики и вектора изменения показателей движения населения. Детальное региональное исследование динамики населения в последние годы выполнено Краснокутская Н. С. [4].
Главная задача настоящей статьи состоит в определении параметров естественного движения населения на территории Северного Кавказа в постсоветский период. Регион рассматривается в географических пределах Чеченской Республики, Республики Дагестан, Республики Ингушетия, Республики Северной Осетии - Алании, Республики Кабардино-Балкарии, Республики Карачаево-Черкесии, Республики Адыгея, Краснодарского и Ставропольского краев.

Второй важной задачей является выявление региональной, субрегиональной и поселенческой специфики естественного воспроизводства населения в самом многонациональном регионе Рос-

() Казалиева А.В., Миненкова В.В., 2020

\ Казалиева Анна Васильевна, e-mail: kazalieva.an@yandex.ru Контент доступен под лицензией Creative Commons Attribution 4.0 License. 
сии. Для этого население изучаемого Северного Кавказа представлено как суммарно, так и в разрезе каждого субъекта, выделены категории городских и сельских жителей.

\section{МАТЕРИАЛЫ И МЕТОДЫ}

По итогам последней всесоюзной переписи населения 1989 года численность населения Северного Кавказа составила 12,4 млн. человек.

За последние 30 лет численность населения Северокавказского региона увеличилась на $28 \%$ с 12,4 млн. чел. в 1989 году до 16,0 млн. чел. в 2019 году.

Распад Советского союза в 1991 году и провозглашение независимости ряда бывших союзных республик повлекли множество социальноэкономических проблем.

За первые постсоветские 13 лет численность населения РФ снизилась на 2,2 млн. человек. Естественный прирост населения на Северном Кавказе сократился до минимума, а в некоторых субъектах достиг отрицательного значения. Так, убыль населения Ставропольского края к концу 90-х годов составила 122 тысячи человек.

Несмотря на это, к 2002 году общая численность населения Северного Кавказа увеличилась до 14,5 млн. человек, что на $16,6 \%$ больше показателя 1989 года. Данный рост произошел на фоне снижения общероссийской численности населения за тот же период на $1,3 \%$ (с 147,4 млн. до 145,5 млн. чел.).

В постсоветский период регионы Северного Кавказа по характеру своего демографического развития разделились на два типа: русскоязычные регионы характеризовались устойчивой естественной убылью, а в национальных республиках положительный естественный прирост сохранялся.

В области миграции ситуация была иной. В 90-е годы население Краснодарского и Ставропольского края пополнялось за счет миграций. Положительное миграционное сальдо отмечалось и в республиках Дагестан, Ингушетия и Адыгея. Миграционный поток в Дагестан и Ингушетию формировался в основном представителями титульных народов, возвращающихся на свою этническую родину. В то же время наблюдался отток русскоязычного населения из национальных республик, что в последствии значительно изменило этническую структуру региона [1]. Миграционный приток населения в Адыгее формировался за счет русскоязычного населения.
Рост населения Северного Кавказа продолжался и в последующие годы. К переписи населения 2010 года численность его увеличилась на $21 \%$, а к 2019 году выросло уже на $28 \%$.

Наиболее быстрыми темпами росло население национальных субъектов Северного Кавказа. Так, с 1989 по 2019 год количество жителей Республики Дагестан выросло на 71,2\%, Кабардино-Балкарии - на 13,9\%, Карачаево-Черкессии - на 11,5\%, Северной Осетии - на 10,3\%. Население Чеченской республики с 2002 по 2019 год увеличилось на треть.

В тоже время население русскоязычных субъектов, в первую очередь Ставропольского края, снизилось на 2,2\%, а численность населения Краснодарского края возросла на 10,5\% исключительно благодаря положительному миграционному сальдо.

Сущий С. Я. классифицировал субъекты Северного Кавказа по демографическим характеристикам следующим образом.

1. Субъекты с высокими темпами естественного прироста населения (Чеченская республика, Ингушетия и Дагестан).

2. Субъекты с небольшим положительным коэффициентом естественного прироста (Кабардино-Балкария, Карачаево-Черкессия и Северная Осетия).

3. Субъекты с отрицательным коэффициентом естественного прироста (Адыгея, Краснодарский и Ставропольский края) [6].

В качестве источников для расчета показателей естественного движения населения необходимы ежегодные данные об общей численности населения, сведения о количестве родившихся и умерших за каждый год. С 1990 года все необходимые данные опубликованы в открытом доступе на официальном сайте Федеральной службы государственной статистки в системе ЕМИСС. Данные из этого источника позволили построить и отразить в таблицах 2-4 динамические ряды показателей естественного движения населения за период с 1990 по 2018 год по всему населению и в разбивке по-городскому и сельскому населению по каждому субъекту Северного Кавказа, а также в сравнении со среднероссийскими показателями.

\section{ОБСУЖДЕНИЕ РЕЗУЛЬТАТОВ}

Коэффициенты рождаемости имеют отчетливую региональную дифференциацию. Субъекты, в которых преобладает русскоязычное население имеют 
более низкие коэффициенты рождаемости, тогда как в национальных - показатели значительно выше.

В первые пять лет после распада СССР коэффициенты рождаемости держались на значительно высоком уровне во всех субъектах региона, но заметно снизились к началу 2000-х годов. В первое десятилетие 21 столетия коэффициенты рождаемости стали расти, достигнув в большей части своего максимума к 2010 году. В последние годы наблюдается очередное снижение количества рождений, а в некоторых субъектах коэффициенты рождаемости опустились до уровня 2000-го года.

Рождаемость в Республике Адыгея в начале 90-х находилась на уровне выше среднероссийского, но соответствовала уровню русскоязычных регионов Северного Кавказа. В 1990 году рождаемость достигала $14,2 \%$, постепенно снижаясь и достигла своего минимума 8,6\% в 1999 году. Максимальный показатель здесь был зафиксирован в 2010 году - 12,9\%о. С 2012 года наблюдается постепенное снижение общего коэффициента рождаемости. В 2018 году он равнялся 9,9\%о. Коэффициент рождаемости в сельской местности заметно превышал городской показатель. Наиболее высокий средний коэффициент рождаемости в постсоветский период в Адыгее был зафиксирован в 2008-2013 годах - 12,7\%o. В городской местности показатель достигал своего максимума в 2008-2013 и 2014-2018 годах - 12\%о, а в сельской местности максимальные значения коэффициента рождаемости отмечались в 2008-2013 годах, когда он достигал $13,4 \%$.

Аналогичная ситуация складывалась в Краснодарском и Ставропольском краях. В Краснодарском крае наибольший средний коэффициент рождаемости наблюдался в 2014-2018 годах - 12,7\% , наименьший в 1996-2001 годах - 8,9\%о. В 20082013 и 2014-2018 годах количество рожденных детей в городе было значительно больше, чем в сельской местности. Основная причина такой ситуации связана с интенсивной миграцией населения в города как в пределах Краснодарского края, так и приток населения из северных и восточных регионов России.

Общий коэффициент рождаемости Ставропольского края не сильно отличается от уровня Краснодарского края. Наибольший средний коэффициент - 12,3\% - зафиксирован в 2014-2018 годах, наименьший в 1996-2001 годах - 8,9\%о. В Кабардино-Балкарии, Карачаево-Черкессии и Северной Осетии ситуация в области рождаемости несколько лучше, чем в русскоязычных субъектах
Северного Кавказа. Наибольшее количество новорожденных на 1000 чел. населения пришлось на 2008-2013 годах: в Кабардино-Балкарии - 14,9, в Карачаево-Черкессии - 13,4, в Северной Осетии 14,6 . Количество рождений в сельской местности в данных республиках традиционно выше, чем в городской местности.

Традиционный семейный уклад и устойчивость религиозных взглядов и обычаев в Республиках Дагестан, Ингушетия и Чечне способствуют более высокому уровню рождаемости, чем в других регионах страны. По количеству новорожденных в общероссийских масштабах лидирует Чеченская Республика с максимальным средним показателем - 28,2 на 1000 населения в 20082013 годах. В эти же годы наибольший средний коэффициент рождаемости в Ингушетии составил $23,8 \%$, в Дагестане - 18,3\%o. В городской местности Чеченской Республики рождается больше детей, чем в сельской. В 2002-2007 годах было зафиксировано 30,8 случаев рождения на 1000 населения, тогда как в Ингушетии и Дагестане в эти годы зафиксирован провал по количеству рождений в городе - $16,2 \%$ и $13,4 \%$ соответственно. В Дагестане и Ингушетии число рождений в селе традиционно превышает число рождений в городе.

В 2018 году Чеченская Республика стала лидером в России по количеству новорожденных - 20,7 на 1000 населения. Несмотря на благоприятную ситуацию в области рождаемости в национальных регионах Северного Кавказа наблюдается постепенное снижение уровня рождаемости. Следует принять во внимание, что в Дагестане вошли в репродуктивный возраст дети людей, которые в начале 90-х массово переселялись из сел в города. Это может несколько менять семейные ценности и репродуктивные установки дагестанских городских жителей. В Ингушетии так же происходит снижение числа рождений. Учитывая, что Ингушетия - регион с молодым населением, которое с целью трудоустройства и обучения в учебных заведениях мигрирует в более благополучные в социально-экономическом плане регионы России, в случае возвращения на родину имеет более широкий кругозор и иные приоритеты. Кавказский традиционализм в этих условиях не исчезнет, но может претерпеть значительную трансформацию.

При этом уровень смертности на Северном Кавказе так же имеет неодинаковую тенденцию в разных его регионах.

Так, общий коэффициент смертности с 19901995 до 2002-2007 годов увеличился: в Краснодар- 
ском крае на 4,1\%, в Ставропольском крае на $12,7 \%$, в Адыгее на 8,6\%, в Кабардино-Балкария на $8,6 \%$, в Карачаево-Черкессия на $18,9 \%$ и в Северной Осетии на 7,1\%. Но в Дагестане, Ингушетии и Чечне, общий коэффициент смертности за этот же период снизился на $13,2 \%, 40 \%$ и $31,7 \%$ соответственно. Одной из причин снижение показателей смертности в этих регионах является непопулярность потребление спиртного, что минимизирует смертность от алкогольных отравлений и ДТП в состоянии алкогольного опьянения, что достаточно распространено в русскоязычных субъектах страны.

В период с 2008 по 2013 год показатели смертности в этих субъектах продолжили снижаться, достигнув к 2018 году минимальных своих показателей не только на Северном Кавказе, по и в целом по стране. Наименьший коэффициент смертности зафиксирован в городской местности в Республике Ингушетия в 2018 году - 2,9 случаев смерти на 1000 населения. Средний коэффициент смертности в данной республике за период 20142018 годы составил 3,3\% .

Наиболее высокий уровень смертности на протяжении всего исследуемого периода наблюдался в Республике Адыгея. В 2014-2018 годах средний коэффициент смертности здесь составил $12,8 \%$, в сельской местности он достиг 13,2\% . Далее следует Краснодарский край с показателем 12,6\% , Ставропольский край - 11,5\%о, Северная Осетия $-10,5 \%$.

Рассматривая динамику смертности в 19902018 годах, дифференцированную по городской и сельской местности, выясняется, что смертность на Северном Кавказе не только в региональном масштабе, но и в сельской и городской местности постоянно держалась на уровне, более низком чем в среднем по России. В национальных субъектах: Чечня, Ингушетия и Дагестан показатели минимальны, а в Адыгее, Краснодарском крае и Ставропольском крае - более высокие и близкие друг к другу. Показатель смертности в Кабардино-Балкарии, Карачаево-Черкессии и Северной Осетии находится на среднем уровне.

В целом сравнивая показатели начального и заключительного этапов изучаемого периода, можно сделать вывод, что наблюдается сокращение смертности во всех регионах Северного Кавказа. Ситуацию портит скачок смертности в период наиболее сложного этапа для страны с 1996-2001 и его последствия, отразившиеся на показателях 2002-2007 годах.
Переходя к показателям естественного прироста населения, необходимо отметить, что в целом по Северному Кавказу наблюдался интенсивный прирост населения, имеющий, однако, отчетливые региональные различия [3].

Вследствие сочетания высокого уровня рождаемости и низкого показателя смертности, естественный прирост в Чечне, Ингушетии и Дагестане достигал значительного масштаба.

Чеченская Республика на протяжении всего изучаемого периода имела самый высокий прирост населения по сравнению с другими субъектами Северного Кавказа, даже несмотря на то, что с 1993 по 2001 годах статистических данных по данной республике не имеется. Наибольший естественный прирост пришелся на 2008-2013 годы - 23,0\%о. С минимальными отличиями показателя следует Республика Ингушетия. Наибольшие коэффициенты естественного пророста приходятся на 20082013 годы - в среднем 19,8\%о. На эти же годы пришелся максимальный средний показатель естественного прироста и в Республике Дагестан $12,6 \%$.

Что касается субъектов Северного Кавказа, населенного преимущественно русскими, то здесь показатель естественного прироста соответствует общероссийскому. В неблагоприятном положении находится Республика Адыгея, где в 2014-2018 годах продолжалась стабильная естественная убыль населения. С 1991 года в регионе не было зафиксировано прироста населения. Несколько лучше ситуация в Ставропольском и Краснодарском крае. В Краснодарском крае с 2013 по 2016 годы наблюдался прирост населения в среднем на $0,4 \%$. С 2017 года естественный прирост населения происходит только в городской местности. Однако рост населения отмечается лишь за счет большого числа мигрантов, устремившихся в последние годы в Краснодарский край [2]. Большинство прибывших в край переселенцев находятся в молодом репродуктивном возрасте, что приводит к увеличению «обшей массы» населения. Уровень смертности несколько снижается, а рождаемость остается на прежнем уровне, вследствие чего и наблюдается незначительный естественный прирост [5].

В Ставропольском крае естественный прирост населения наблюдался с 2012 по 2017 годы, в среднем на $1 \%$, но уже в 2018 году зафиксирована убыль населения в размере $0,5 \%$.

В Северной Осетии естественная убыль населения происходила в 1996-2001 и 2002-2007 годах. Однако с 2008 года наблюдается стабильный ес- 
тественный прирост населения в диапазоне 2,2$4,6 \%$.

Показатели естественного прироста в Кабардино-Балкарии и Карачаево-Черкессии так же имели отрицательное значение в отдельные годы, которые пришлись на конец 90-х начало 2000-х, но с 2004-го года в Карачаево-Черкессии, а с 2007 года и в Кабардино-Балкарии происходит стабильный естественный прирост населения, в среднем на $3 \%$ и $5 \%$ в год соответственно.

\section{ЗАКЛЮЧЕНИЕ}

Постсоветский период связан с заметным сокращением рождаемости и увеличением уровня смертности, что повлекло снижение коэффициента естественного прироста в большинстве субъектов Северного Кавказа. Вместе с тем, наблюдалось превышение рождаемости над смертностью, что давало положительные показатели репродуктивной активности в макрорегионе. В то же время выявляется заметная разница между субъектами Северного Кавказа в разрезе конкретных показателей, что объясняется социокультурными и социально-экономическими особенностями жизни населения. Наиболее высокими показателями естественного движения населения выделяется Чеченская Республика и Ингушетия, где естественный прирост часто превышал $20 \%$. В последние годы естественное воспроизводство населения этих республик, а также Дагестана стабилизируется, снижается уровень естественного прироста, но есть все основания полагать, что данный рост будет стабилен и в будущем. Гораздо хуже обстоят дела в плане воспроизводства населения в Республике Адыгея, Краснодарском и Ставропольском краях.

Меры, предпринимаемые правительством России в отношении стимулирования рождаемости в последнее десятилетие, подстегнуло только репродуктивную активность в национальных республиках, традиционно рассматривающих воспроизводство населения как центральный приоритет своего развития. На русскоязычное население данные меры подействовали незначительно.

\section{СПИСОК ЛИТЕРАТУРЫ}

1. Алиева В.Ф. Демографические прочессы в современном Дагестане. Москва, Наука, 2007. 326 с.

2. Казалиева А. В. Динамика демографической ситуации в регионах северокавказского экономического района // Миграционные процессы: проблемы адаптациии и интегращчии мигрантов, 2018, с. 402-408

3. Казалиева А. В., Миненкова В. В., Мамонова А. В. Ретроспективный анализ динамики изменения численности населения Северного Кавказа // Известия Дагестанского государственного педагогического университета. Естественные и точные науки, 2018, т. 12, № 2, c. $89-94$.

4. Краснокутская Н. С. Факторы демографического развития Луганского региона: общественно-географический аспект // Вестник Воронежского государственного университета. Серия: География. Геоэкология, 2020, № 1, c. 48-57. DOI: https://doi.org/10.17308/ geo. $2020.1 / 2661$

5. Миненкова В. В., Мамонова А. В. Миграции как причина роста численности населения Краснодарского края // Миграционные прочессы: проблемы адаптацчии и интеграцчии мигрантов, 2018, с. 204-208.

6. Сущий С.Я. Динамика населения юга России в постсоветский период (основные тенденции) // Экономика развития региона: проблемы, поиски, перспективbl, 2011, № 12, c. 262-270.

Конфликт интересов: Авторы декларируют отсутствие явных и потенциальных конфликтов интересов, связанных с публикацией настоящей статьи.

Поступила в редакичию 05.12.2019 Принята к публикации: 26.07.2020 


\title{
Dynamics of Natural Population Movement in the North Caucasus in the Post-Soviet Period
}

\author{
A. V. Kazalieva ${ }^{\bowtie}$, V. V. Minenkova \\ Kuban State University, Russian Federation \\ (149, Stavropolskaya st., Krasnodar, 350040)
}

\begin{abstract}
The purpose is to analyze the ratio of total birth and death rates, which allowed us to present an overall picture of population changes because of natural population movement in the national republics of the North Caucasus, as well as in the Stavropol and Krasnodar territories in the post-Soviet period. Based on the analysis of the natural movement coefficients of the population, to reveal the main patterns and trends of reproduction in the regional and sub-regional structure. Methods. The indicators are summarized in time series and also distributed among urban and rural settlements. Results. Birth, death and natural growth rates in the North Caucasus have a pronounced regional differentiation, which has become more evident in recent years. Despite the fact that today the analyzed indicators have a General tendency to a gradual decrease, in the first two decades after the collapse of the USSR, a number of national subjects of the North Caucasus experienced a demographic "explosion" against the background of zero natural growth in Russian-speaking regions. The settlement specificity of natural reproduction of the population was also revealed. In the Russian-speaking Stavropol and Krasnodar territories, as well as in the republics of Adygea and North Ossetia, natural growth is higher among the urban population, while in the rest of the North Caucasus, natural growth in rural areas is higher than in urban areas.
\end{abstract}

Key words: birth rate, mortality, natural reproduction, natural population movement, urban population, rural population, North Caucasus.

For citation: Kazalieva A. V., Minenkova V. V. Dynamics of natural population movement in the North Caucasus in the post-Soviet period. Vestnik Voronezskogo gosudarstvennogo universiteta. Geografia geoekologia, 2020, No. 3, pp. 49-55. (In Russ.) DOI: https://doi.org/10.17308/geo.2020.3/3023

\section{REFERENCES}

1. Alieva V.F. Demograficheskie processi v sovremennom Dagestane [Demographic processes in modern Dagestan]. Moscow, Nauka, 2007. 326 p. (In Russ.)

2. Kazalieva A. V. [Dynamics of the demographic situation in the regions of the North Caucasian economic region] Migracionnie processi: problemi adaptacii i integracii migrantov [Migration processes: problems of adaptation and integration of migrants], 2018. pp. 402-408. (In Russ.)

3. Kazalieva A. V., Minenkova V. V., Mamonova A. V. Retrospektivniy analiz dinamiki izmeneniya chislennosti naseleniya Severnogo Kavkaza [Retrospective analysis of the dynamics of changes in the population of the North Caucasus]. Izvestiya Dagestanskogo gosudarstvennogo pedagogicheskogo universiteta. Estestvennie i tochnie nau$k i, 2018$, v. 12. no. 2, pp. 89-94. (In Russ.)

4. Krasnokutskaya N. S. Faktory demograficheskogo razvitiya Luganskogo regiona: obshchestvenno-ge-

(C) Kazalieva A. V., Minenkova V.V., 2020

凶 Anna V. Kazalieva, e-mail: kazalieva.an@yandex.ru ograficheskiy aspekt [Factors of Demographic Development of the Lugansk Region: Social and Geographic Aspect]. Vestnik Voronezskogo gosudarstvennogo universiteta. Geografia geoekologia, 2020, no. 1, pp. 48-57. (In Russ.) DOI: https://doi.org/10.17308/geo.2020.1/2661

5. Minenkova V. V., Mamonova A. V. [Migration as a cause of population growth in the Krasnodar Territory]. Migracionnie processi: problemi adaptacii i integracii migrantov [Migration processes: problems of adaptation and integration of migrants], 2018, pp. 204-208. (In Russ.)

6. Suschii S. Ya. Dinamika naseleniya yuga Rossii v postsovetskii period (osnovnie tendencii) [Population dynamics of southern Russia in the post-Soviet period (main trends)]. Ekonomika razvitiya regiona: problem, poiski, perspektivi, 2011, no. 12. pp. 262-270. (In Russ.)

Conflict of interests: The authors declare no information of obvious and potential conflicts of interest related to the publication of this article.

Received: 05.12.2019

Accepted: 26.07 .2020

The content is available under Creative Commons Attribution 4.0 License. 
Казалиева Анна Васильевна

аспирант кафедры экономической, социальной и политической географии, Институт географии, геологии, туризма и сервиса, Кубанский государственный университет, г. Краснодар, Российская Федерация, ORCID: https://orcid.org/0000-0002-5511-1643, e-mail: kazalieva.an@yandex.ru

Миненкова Вера Владимировна

кандидат географических наук, доцент, заведующий кафедрой экономической, социальной и политической географии, Институт географии, геологии, туризма и сервиса, Кубанский государственный университет, г. Краснодар, Российская Федерация, ORCID: https://orcid.org/0000-0003-4184-252, e-mail: minenkova@inbox.ru
Anna V. Kazalieva

Post-graduate student of the Department of Economic, Social and Political Geography of the Institute of Geography, Geology, Tourism and Service, Kuban State University, Krasnodar, Russian Federation, ORCID:

https://orcid.org/0000-0002-5511-1643, e-mail:

kazalieva.an@yandex.ru

Vera V. Minenkova

Cand. (Geogr.) Sci., Associate Professor, the Head of the Department of Economic, Social and Political Geography of the Institute of Geography, Geology, Tourism and Service, Kuban State University, Krasnodar, Russian Federation, ORCID: https://orcid.org/0000-0003-4184-252, e-mail: minenkova@inbox.ru 